Article

\title{
Optimization of In Vitro Mycobacterium avium and Mycobacterium intracellulare Growth Assays for Therapeutic Development
}

\author{
Lauren Auster ${ }^{1}$, Morgan Sutton ${ }^{1}$, Mary Chandler Gwin ${ }^{1} \mathbb{D}$, Christopher Nitkin ${ }^{1,2}$ and \\ Tracey L. Bonfield 1,*(D) \\ 1 Division of Pulmonology, Allergy and Immunology, Department of Pediatrics, Case Western Reserve \\ University School of Medicine, 10900 Euclid Ave. BRB 822, Cleveland, OH 44106, USA; \\ Lauren.Auster@case.edu (L.A.); mxs1175@case.edu (M.S.); mary.gwin@yale.edu (M.C.G.); \\ crnitkin@chm.edu (C.N.) \\ 2 Division of Neonatology, Department of Pediatrics, Children's Mercy Hospital, University of \\ Missouri-Kansas City School of Medicine, 2401 Gillham Rd., Kansas City, MO 64108, USA \\ * Correspondence: Tracey.Bonfield@case.edu; Tel.: +216-368-4558; Fax: +216-368-4223
}

Received: 17 December 2018; Accepted: 20 January 2019; Published: 1 February 2019

\begin{abstract}
Infection with nontuberculous mycobacteria (NTM) is a complication of lung disease in immunocompromised patients, including those with human immunodeficiency virus and acquired immune deficiency syndrome (HIV / AIDS), chronic obstructive pulmonary disease (COPD), and cystic fibrosis (CF). The most widespread, disease-causing NTM is Mycobacterium avium complex $(M A C)$, which colonizes the lungs as a combination of Mycobacterium avium, Mycobacterium intracellulare, and other mycobacterial species. While combination drug therapy exists for $M A C$ colonization, there is no cure. Therapeutic development to treat $M A C$ has been difficult because of the slow-growing nature of the bacterial complex, limiting the ability to characterize the bacteria's growth in response to new therapeutics. The development of a technology that allows observation of both the MAC predominant strains and $M A C$ could provide a means to develop new therapeutics to treat NTM. We have developed a new methodology in which M. avium and M. intracellulare can be optimally grown in short term culture to study each strain independently and in combination, as a monitor of growth kinetics and efficient therapeutic testing protocols.
\end{abstract}

Keywords: Mycobacterium intracellulare; Mycobacterium avium; optimized growth; anti-non-tuberculous mycobacterium therapeutic testing

\section{Introduction}

Mycobacterial species not belonging to Mycobacterium tuberculosis or Mycobacterium leprae are designated nontuberculous mycobacteria (NTM). NTM are pervasive in the environment and contribute to pulmonary disease in immunocompromised patients including diseases such as cystic fibrosis (CF) and acquired immunodeficiency syndrome (AIDS) [1]. The most common, disease-causing NTM is Mycobacterium avium complex (MAC), a slow-growing symbiotic combination of Mycobacterium avium and Mycobacterium intracellulare, with other non-tuberculosis species being least dominant [1,2]. Due to the emergence of the AIDS epidemic, contracting HIV is the most significant risk factor for $M A C$ infection [3]. Infection with NTM is also common in patients with CF, including M. avium and $M$. intracellulare, the latter being more prominent in severe pulmonary disease [4]. Further, patients with a history of lung disease, such as chronic obstructive pulmonary disease (COPD), tuberculosis (TB), or pneumonia [5,6] and idiopathic pulmonary fibrosis (IPF) demonstrated an increased propensity for NTM colonization [7]. 
Traditionally, NTM and MAC therapeutic testing studies have focused on $M$. avium, not particularly separating M. avium from M. intracellulare [8,9]. Drug therapy for $M A C$ infection includes gentamicin, clarithromycin, azithromycin, rifampin, rifabutin, ethambutol, and streptomycin [10]. Unfortunately, treatment of $M A C$ often yields poor results, possibly due to the toxicity of higher dosages of these drugs and their inherent pharmacology [11]. The limitations of dosage based on toxicity can result in poor therapeutic testing sensitivity as well as an inability to monitor multiple therapeutic treatment drug interactions. Patients with $M$. intracellulare lung disease tend to present with more severe infection symptoms and $M$. intracellulare prognosis than those with M. avium lung disease, suggesting that therapeutic development which might differentiate or distinguish the two strains would be therapeutically beneficial [12], with patient-specific therapeutic application done post-colonization identification. Since methods that compare M. avium and M. intracellulare are currently time consuming and not necessarily pathogen specific [13], we developed a new and innovative protocol which can speed up the growth kinetics for therapeutic testing in short term in vitro quantitative assays. $M$. intracellulare, $M$. avium, and $M A C[8,9,14]$ typically take $2-3$ weeks to grow in the traditional solid media phase, whereas broth media can produce more rapid results [1]. Both methods use media optimized for mycobacterial growth, most commonly 7H9 broth and 7H10 agar plates $[1,8,9,14]$. In these studies, we utilized gentamicin as a sub-optimal antibiotic to monitor the sensitivity of the assays overall. Since $M A C$ is primarily composed of M. avium and M. intracellulare [1,2], our protocol demonstrates the capability to optimize the growth and characterization of each of these strains independently and in combination for systematic development of therapeutic drug testing using cost-effective, highly sensitive quantitative measures of growth assessment.

\section{Materials and Methods}

\subsection{Preparation of $7 H 9$ Broth with ADC Enrichment}

Broth was prepared according to American Type Culture Collection (ATCC) guidelines [15]. To make the initial 7H9 broth, $2.35 \mathrm{~g} 7 \mathrm{H} 9$ broth base, $2.0 \mathrm{~mL}$ glycerol, and $450 \mathrm{~mL}$ deionized water were combined in a glass bottle and autoclaved on a liquid cycle. After cooling to $45-50{ }^{\circ} \mathrm{C}, 50 \mathrm{~mL}$ of ADC Enrichment was aseptically added and mixed. The entire 7H9 broth with ADC Enrichment was filter sterilized and stored in a large, glass round bottle at $2-8{ }^{\circ} \mathrm{C}$ prior to utilization in monitoring colony forming units (CFUs) of each pathogen. All culture conditions were done at homeostatic $\mathrm{pH}$ 7.5 to minimize the variability of pathogen response.

\subsection{Initial Bacterial Preparation and Preservation}

Freeze-dried M. avium and M. intracellulare were removed from packaging using the double-vial preparation instructional guide from the ATCC [16]. Each pellet was rehydrated by adding $0.5-1 \mathrm{~mL}$ of enriched 7H9 broth from an individual 5-6 mL aliquot of broth and then aseptically transferred into the aliquot flask after mixing. The bacterial flasks were incubated at $37^{\circ} \mathrm{C}$ in a shaking incubator for one week, for stabilization in culture prior to initiation into the therapeutic testing protocols or freezing protocols for future studies. All studies were standardized against growth medium as the baseline control.

\subsection{Optical Density}

Optical density (OD) was measured using the Beckman DU 530 UV/VIS Spectrophotometer (Beckman Coulter, Brea, CA) at each time point throughout the experiment. Five time points at $18 \mathrm{~h}$ apart were chosen based on generation of growth curves from start to cessation of growth. Samples $(1 \mathrm{~mL})$ from each bacterial flask were transferred to cuvettes for the ability to refract light at $600 \mathrm{~nm}$ and returned to their respective flasks. OD provides insight into the bacterial growth prior to receiving CFU data (see Section 2.4 Colony Forming Units). Comparisons were made between the variables using the culture medium as a control. 


\subsection{Colony Forming Units}

Colony forming units (CFU) were measured one time point per day throughout each of the individual experiments. The bacteria were evaluated over several dilutions to define the best end-point for quantitative measurement. The final studies utilized $10^{-6}$ and $10^{-7}$ dilution in phosphate buffered saline (PBS) and were grown in duplicate $(10 \mu \mathrm{L} /$ column) on 7H10 Middlebrook agar plates (Teknova, Hollister, CA, USA). The plates were incubated at $37^{\circ} \mathrm{C}$ for one week followed by an assessment of CFUs by at least two different counters. Comparisons were made utilizing the culture medium as a control.

\subsection{Resazurin Assay}

The kinetics of bacterial growth was monitored using the CellTiter-Blue ${ }^{\circledR}$ Cell Viability Assay [17]. Bacterial samples collected from each time point and monitored in triplicate (50 $\mu \mathrm{L}$ per well) using a 96 well with background controls of PBS and 7H9 broth. After diluting 1:1 with PBS, $20 \mu \mathrm{L}$ cell titer blue was added to quantify bacterial growth by fluorescence using corresponding SoftMax Pro 6.5.1 software (Molecular Devices, Sunnyvale, CA, USA). Comparisons were made utilizing the culture medium as a control.

\subsection{Gentamicin Studies}

Gentamicin was chosen for therapeutic testing in the resazurin, OD, and CFU assays to establish the lower end specificity and sensitivity between presence and absence of a therapeutic in the newly developed growth protocol. M. intracellulare, M. avium, and $M A C$ were grown in the presence and absence of $0.1,0.5,1,5,10,20 \mu \mathrm{g} / \mathrm{mL}$ gentamicin, with antibiotics added on the first day of the 90-hour culture. All comparisons were done against bacteria grown in the basal medium without antibiotics or the culture medium without pathogens.

\subsection{Statistics}

Two-tailed, paired T-test analysis was performed to determine the statistical significance of each assay. All studies were standardized against the growth medium as the baseline control. For the gentamicin dose-response study, two-tailed, paired $T$-test and linear regression analyses were used to identify significance of both the rate of growth and total growth over $90 \mathrm{~h}$, respectively. For therapeutic testing, ANOVA and linear regression analysis were utilized to correlate the different assay formats and end-points. Graphics and statistics were done using GraphPad Prism 7 software (GraphPad Software, San Diego, CA, USA). Asterisks above bars denote statistical significance in each of the datasets.

\section{Results}

\subsection{Optical Density Indicates Increased Bacterial Concentration over $90 \mathrm{~h}$}

The optical density (OD) of samples from each bacterial strain and combination were obtained at several time points spread over a 90 -hour incubation period. The 90 -hour incubation period was chosen due to monitoring of growth kinetics to the cessation point, with 18-hour increments chosen to demonstrate appreciable changes. Using these OD measurements, the growth of M. avium, M. intracellulare, and MAC were evaluated. The two different bacteria demonstrated a similar kinetic trend and increased over $90 \mathrm{~h}$, as shown in Figure 1. Variation between the bacterial strains was minimal, especially up to $45 \mathrm{~h}$, but each strain exhibited a significant increase in OD after $90 \mathrm{~h}$ when compared to the baseline value at time zero $(\mathrm{P}<0.1)$ as shown in Figure 2. M. avium and MAC had less variability in OD and reached higher OD values than $\mathrm{M}$. intracellulare by the conclusion of the experiment, as shown in Figure 1. These studies demonstrate that M. avium and MAC demonstrate more stable growth kinetics than $\mathrm{M}$. intracellulare alone, as defined by less variability and higher OD levels. Over the course of the studies, the OD levels reached saturation, related to the combination of 
live versus dead bacteria and the ability to refract light. With the limitations and lack of specificity of OD, each time point was also followed closely with CFUs (see Section 3.2) throughout the duration of the experiment. This provided the opportunity to define differences between the limitation of detection method and growth cessation.

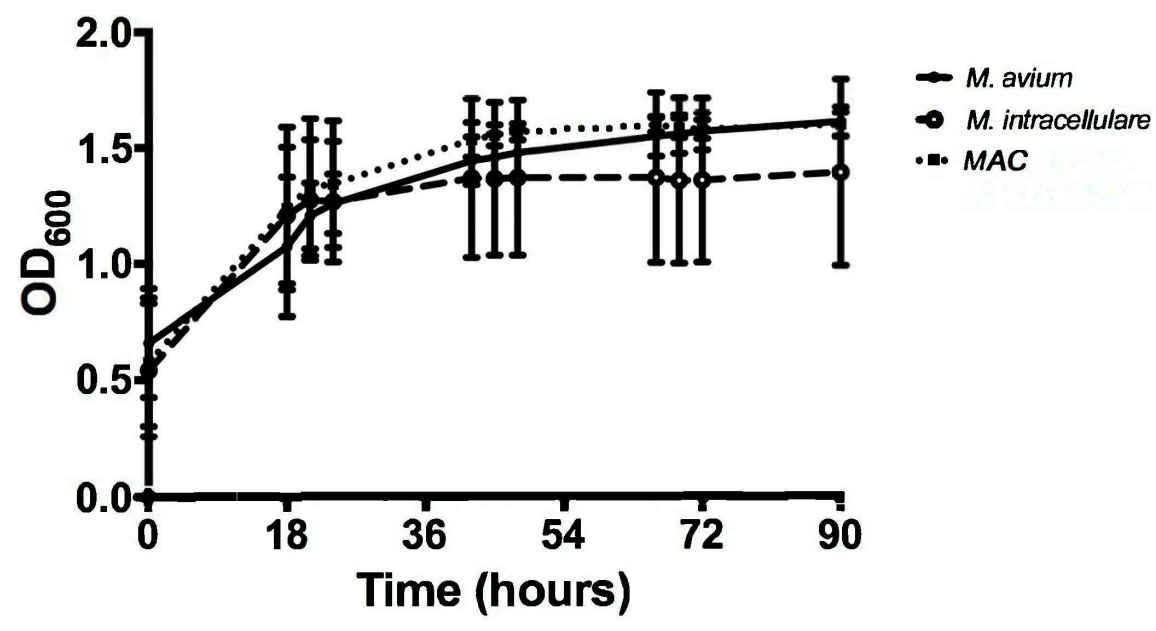

Figure 1. Optical density (OD) kinetics of M. avium (solid line, solid symbol), M. intracellulare (dashed line, open symbol), and MAC (M. avium combined with $M$. intracellulare) (dotted line with solid square symbol) over $90 \mathrm{~h}$ at $600 \mathrm{~nm}, n=7$.

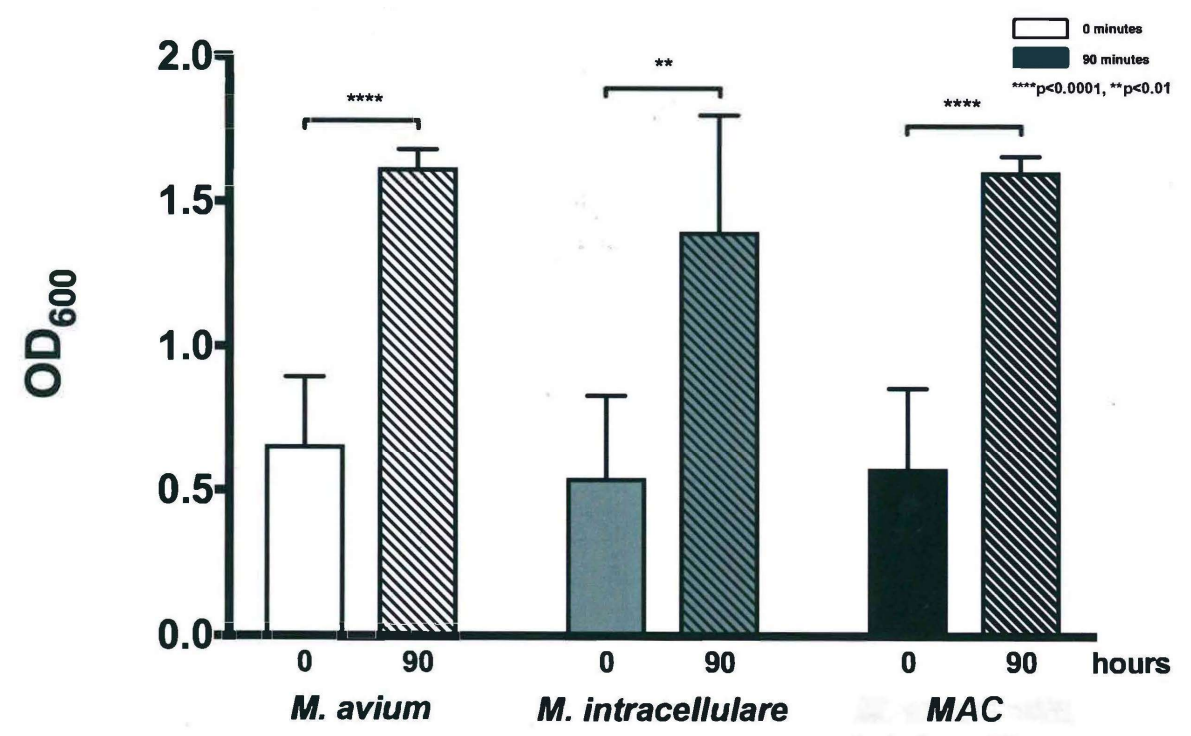

Figure 2. Optical density of M. avium, M. intracellulare, and $M A C$ (M. avium combined with $M$. intracellulare) at time zero and 90 h. M. avium and MAC (M. avium with M. intracellulare) demonstrated increased OD at a significance of ${ }^{* * * *} p<0.0001$ according to two-tailed, paired $T$-test analysis. The increased OD of $M$. intracellulare was also significant, but at ${ }^{* *} p<0.01, n=7$.

\subsection{Colony Forming Units Confirms Bacterial Growth over $90 \mathrm{~h}$}

Colony forming units (CFU) were measured daily throughout the experiment. Dilutions were plated out to both $10^{-6}$ and $10^{-7}$, which enabled bacterial colonies to be counted at different concentrations to determine density impact of the new culturing technology on growth and bacteria phenotypes, as shown in Figure 3. At $10^{-5}$ dilutions, colonies were too numerous to count (TNTC) while at $10^{-8}$ dilutions, no growth was observed. Several dilutions were done during each experiment to gauge the overall impact of the bacterial concentration on CFUs. CFUs that reach a value that 
is too numerous to count (TNTC) within the manuscript are noted as 500 CFU. At $10^{-6}$ dilutions, M. avium exhibited high CFUs and leveled off at 500 CFU after only $20 \mathrm{~h}$ of growth, as shown in Figure 3A. M. intracellulare and MAC demonstrated a steady increase in CFUs over $90 \mathrm{~h}$, but with some variability, as shown in Figure 3A. Similar to the differences seen in OD, M. avium conferred higher CFUs compared to $M$. intracellulare, most likely due to its dominant role in $M A C$. At $10^{-7}$ dilutions, the kinetics of M. avium were more easily observed and indicated a steady increase in CFUs over $90 \mathrm{~h}$, as shown in Figure 3B. M. intracellulare and $M A C$ also had increased CFUs, but at a slower rate over the defined dilutions. $M$. avium has more robust growth kinetics than $M$. intracellulare, so it is plausible that the slower rate of $M A C$ growth over the defined dilutions is due to the combination of the faster and slower growing strains. Measuring CFUs at both $10^{-6}$ and $10^{-7}$ dilutions was pertinent to fully characterizing the growth and the phenotype of the bacteria, as shown in Figure $3 \mathrm{C}$, and to make comparisons between the different bacterial strains and combinations if the colonies ultimately change or look different.

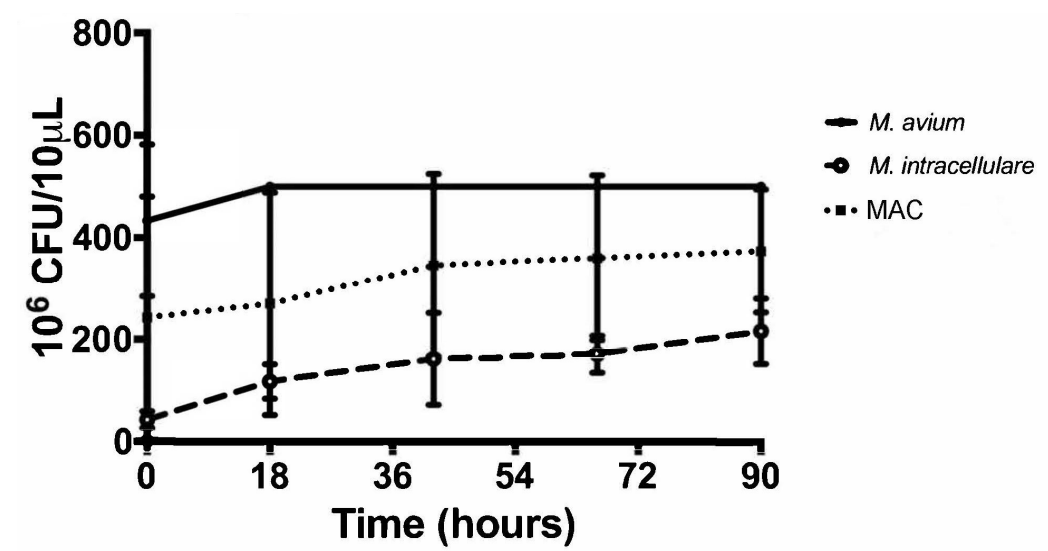

(A)

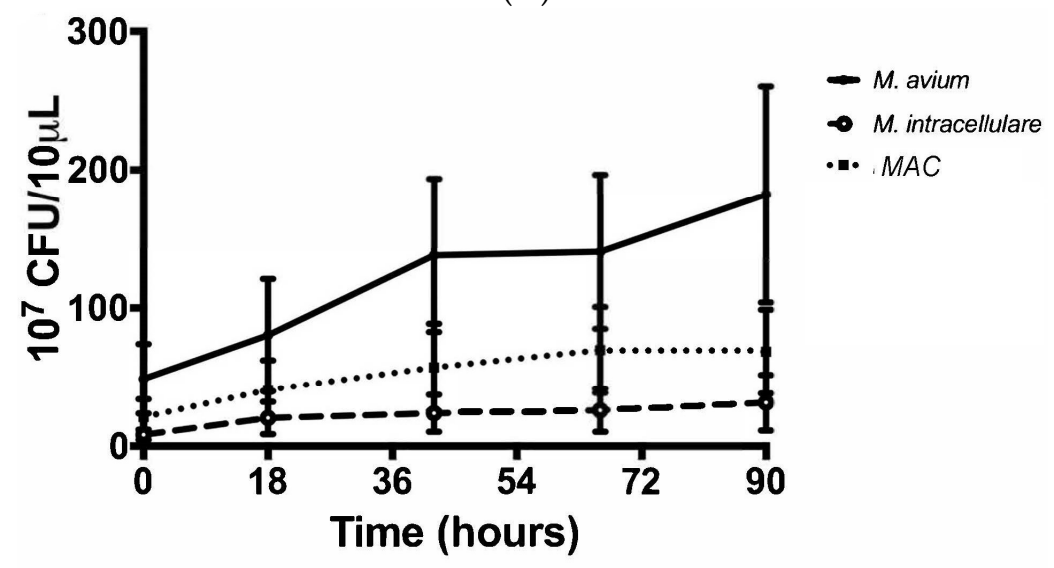

(B)

Figure 3. Cont. 


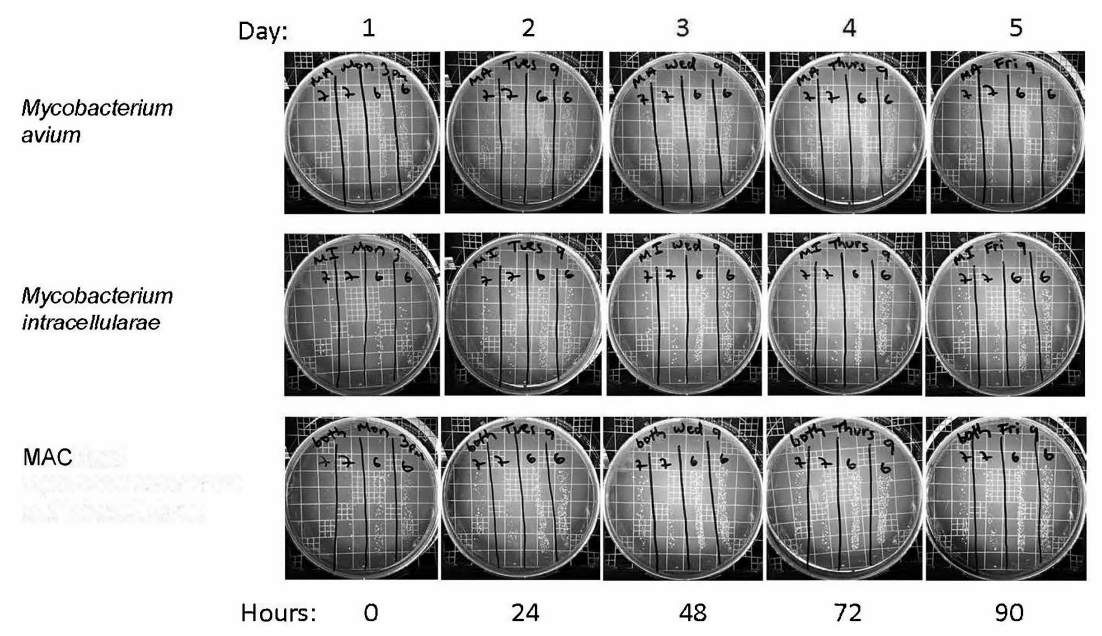

(C)

Figure 3. Bacterial growth kinetics of $M$. avium, M. intracellulare, and $M A C$ (M. avium combined with $M$. intracellulare) over $90 \mathrm{~h}$ at (A) $10^{-6}$ dilutions $(n=7)$; and $(\mathbf{B}) 10^{-7}$ dilutions $(n=7)$. (C) Agarose plates of M. avium, M. intracellulare, and M. avium combined with $M$. intracellulare at $10^{-6}$ and $10^{-7}$ dilutions.

The differences observed between dilutions when comparing CFUs at time zero and after $90 \mathrm{~h}$ for all three groups demonstrated several differences, specifically when you compare the growth at the start of the assay ( 0 minutes, solid bars) to the final growth at the end of the study ( 90 minutes, hatched bars). An increase in CFU of $M$. intracellulare was detected at a (** $p<0.01)$ at $10^{-6}$ and $10^{-7}$ dilutions $(p<0.05)$ while CFU increases were not significant for M. avium and $M A C 10^{-6}$, as shown in Figure 4A. At $10^{-7}$ dilutions, the growth of M. avium and $M A C$ after $90 \mathrm{~h}$ was significant $(p<0.1)$, while growth of $M$. intracellulare alone was significant $(p<0.05)$, as shown in Figure 4B. We noted that the variability in CFUs, particularly for $M A C$, could be influenced by the recycling of bacteria from week to week after they were transferred to new flasks of broth for subsequent experiments. Furthermore, when the bacteria appeared to be growing less effectively after multiple passages, fresh flasks of bacteria were started using frozen aliquots. Overall, M. avium, M. intracellulare, and $M A C$ exhibited increased CFUs over a 90-hour period, indicating growth and colony formation.

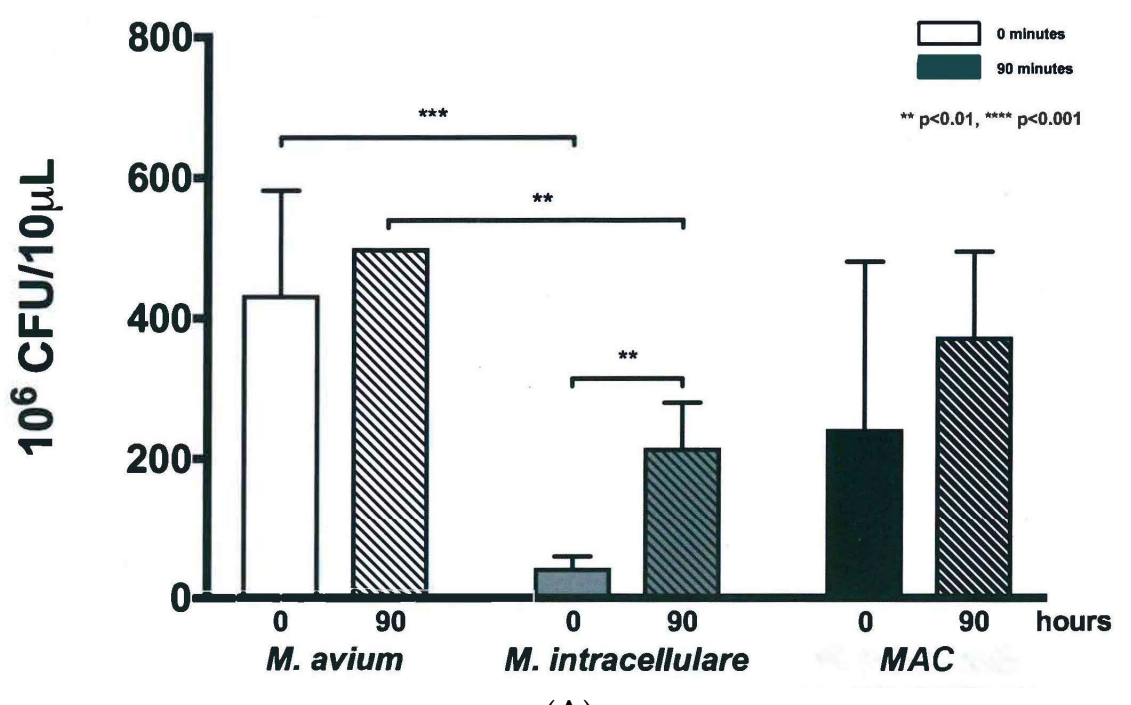

(A)

Figure 4. Cont. 


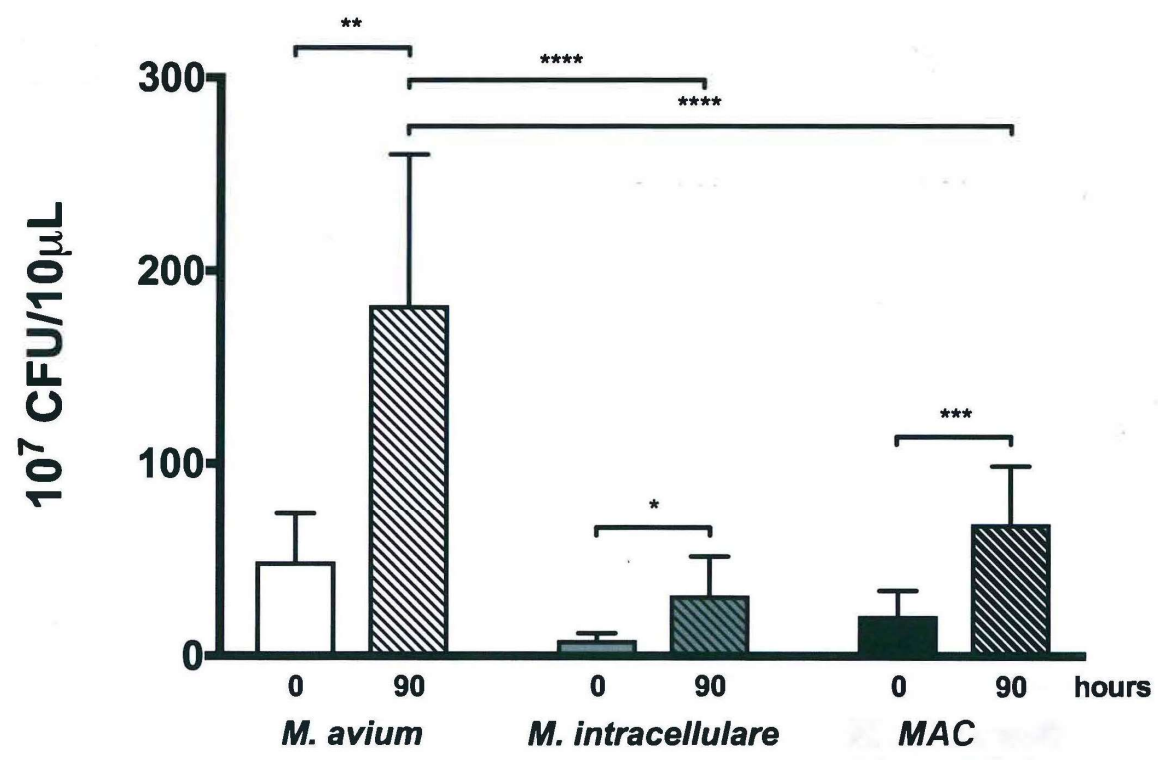

(B)

Figure 4. Bacterial growth of $M$. avium, M. intracellulare, and MAC (M. avium combined with M. intracellulare) at time zero and $90 \mathrm{~h}$ at (A) $10^{-6}$ dilutions. Increased colony forming units (CFUs) after $90 \mathrm{~h}$ were significant for $M$. intracellulare at ${ }^{* *} p<0.01$ according to two-tailed, paired $T$-test analysis. Growth of M. avium and MAC (M. avium with M. intracellulare) after $90 \mathrm{~h}$ was not significant at this dilution. The CFU differences between $M$. avium and $M$. intracellulare were significant at time zero with *** $p<0.001$ and at $90 \mathrm{~h}$ with ${ }^{* *} p<0.01$. (B) $10^{-7}$ dilutions. Increased CFUs after $90 \mathrm{~h}$ were significant for M. avium at ${ }^{* *} p<0.01, M$. intracellulare at $*<0.05$, and MAC (M. avium with M. intracellulare) at ${ }^{* * *}$ $p<0.001$ according to two-tailed, paired T-test analysis. The CFU differences between M. avium and M. intracellulare, and between M. avium and MAC (M. avium with M. intracellulare), were significant at $90 \mathrm{~h}$ with ${ }^{* * *} p<0.0001, n=7$.

\subsection{Resazurin Assay Detects Metabolic Activity of the NTM}

The resazurin assay was performed at the end of each experiment to determine the metabolic activity of each bacterial strain at each time point along the course of the experiment. Samples from each time point throughout the experiment were saved and stored at $4{ }^{\circ} \mathrm{C}$ to be used in the assay. Higher levels of fluorescence indicated greater metabolic activity, relative to the stress of the availability of growth medium and potentially the introduction of growth inhibitors [18]. For all three strains and combinations, metabolic activity appeared to be cyclically consistent with changes in bacterial metabolism associated with cell cycle, as shown in Figure 5. This fluctuation of growth indicates intercellular activity as the bacteria propagated in culture over time [19]. Although metabolic activity fluctuated, fluorescence increased for both $M$. avium and MAC $(p<0.01)$, while it decreased for $M$. intracellulare $(p<0.05)$. However, when a direct comparison was made between the start of the assay and the end of the assay between $M$. avium, M. intracellulare, and the combined $M A C$, the $M$. intracellulare had a modest change, with increases in the $M$. avium-containing cultures (Figure 6). The difference between the bacteria combinations in overall growth may be related to the dominance and growth stability of $M$. avium compared to $M$. intracellulare or the growth condition optimization protocol. $M$. intracellulare may require modifications in growth conditions, which is an on-going focus in our laboratory. 


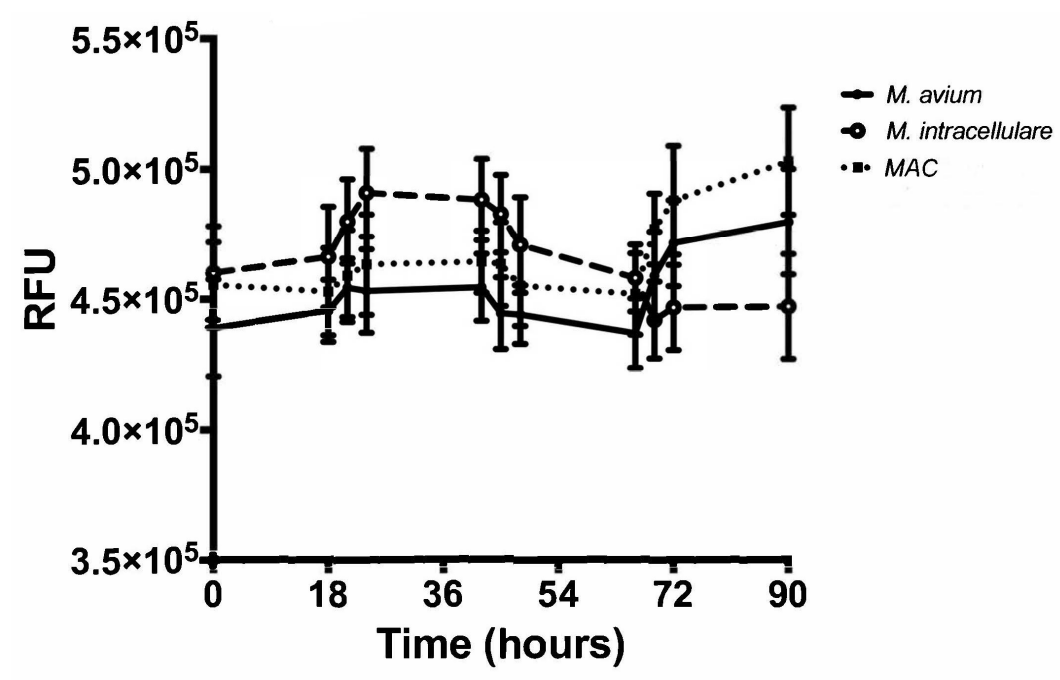

Figure 5. Cellular metabolic activity of $M$. avium, M. intracellulare, and MAC (M. avium combined with M. intracellulare) over $90 \mathrm{~h}$. A cyclic trend was observed, $n=7$.

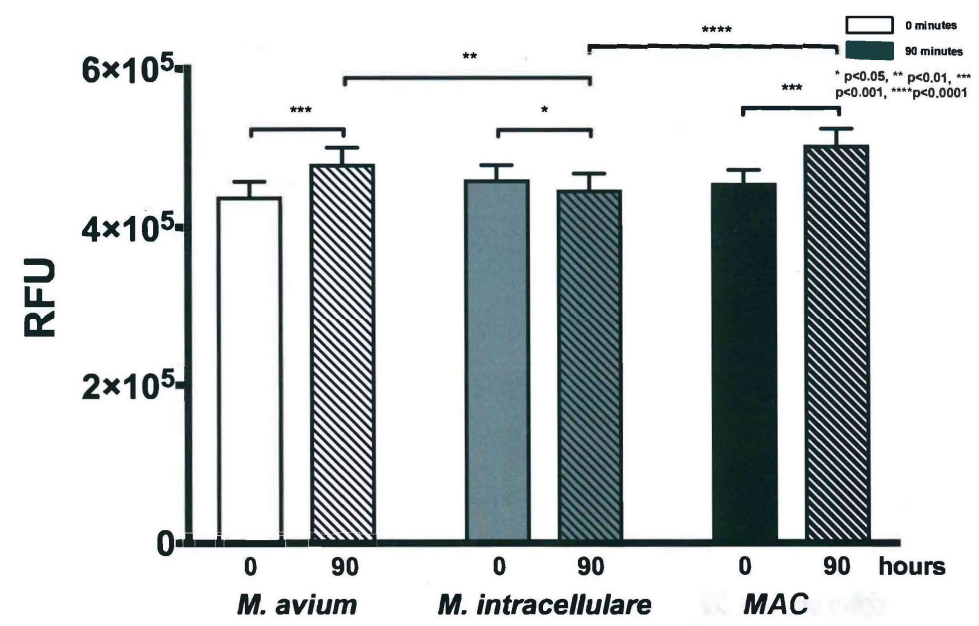

Figure 6. Cellular metabolic activity of M. avium, M. intracellulare, and MAC (M. avium combined with $M$. intracellulare) at time zero and $90 \mathrm{~h}$. Increased activity after $90 \mathrm{~h}$ was significant for $M$. avium at ${ }^{* * *} p<0.001$, M. intracellulare at ${ }^{*} p<0.05$, and MAC (M. avium with M. intracellulare) at ${ }^{* * *} p<0.001$ according to two-tailed, paired $T$-test analysis. Significant differences after $90 \mathrm{~h}$ were observed between M. avium and M. intracellulare at ${ }^{* *} p<0.01$ and between $M$. intracellulare and MAC (M. avium with M. intracellulare) at ${ }^{* * * *} p<0.0001, n=7$.

\subsection{Validation of New Assays to Monitor Therapeutics}

The next focus of the work was to determine how the established growth conditions would impact the ability to detect the impact of anti-NTM therapeutics. M. avium, M. intracellulare, and the combined $M A C$ were cultured in the presence and absence of a sub-optimal antibiotic (gentamicin). The purpose for picking gentamicin was to be able to establish sensitivity and specificity of the new NTM assays, as well as to enable the utilization of combined therapeutics for enhancing current antibiotic sensitivity. $M$. avium $\mathrm{OD}, \mathrm{CFUs}$, and the resazurin assay ultimately revealed distinct differences of detection when treated with dose-escalated concentrations of gentamicin. As the gentamicin dose was increased to $0.5 \mathrm{\mu g} / \mathrm{mL}$ and above, OD returned almost to baseline levels after $90 \mathrm{~h}$. Differences in OD kinetics of each gentamicin treatment were significant according to linear regression analysis, as shown in Figure 7A. To maintain figure clarity, OD mean and standard deviation values are listed in Table 1 . At the end of the experiment, significant increases in OD were observed for only the 0 and $0.1 \mu \mathrm{g} / \mathrm{mL}$ gentamicin treatments, while higher gentamicin doses stunted further M. avium growth, as shown 
in Figure 7B. CFU kinetics displayed a similar trend at both $10^{-6}$ and $10^{-7}$ dilutions, with increased gentamicin doses resulting in decreased or stunted bacterial growth. Differences in CFU growth kinetics were significant according to linear analysis, as shown in Figure 8. Mean and standard deviation values can be found in Tables 2 and 3. After $90 \mathrm{~h}$, CFUs of both dilutions significantly decreased for 5, 10, and $20 \mu \mathrm{g} / \mathrm{mL}$ gentamicin treatments, as shown in Figure 9. Kinetic differences in the resazurin assay were not dose-dependent, likely due to the complexity related to monitoring metabolic activity, stress, and growth at the same time, as shown in Figure 10. The stress-related increase in metabolic activity relative to comparisons between 0 minutes and 90 minutes was consistent across all of the concentrations of gentamicin except for the $0.1 \mu \mathrm{g} / \mathrm{ml}$ dose, as shown in Figure 11A. This variation in gentamicin effects in the resazurin assay could be due to the phase of metabolism of the pathogen. The cyclical phase of $M$. avium demonstrates the highly dynamic nature of metabolic energy released by the pathogen, as shown in Figure 11B. The non-treated M. avium is shown in blue, while the highest dose of gentamicin is shown in red. The stress and impact of the gentamicin over time is evident by the higher values of relative fluorescent units (RFUs) in the culture, which by $90 \mathrm{~h}$ are comparable to just the stress of the culture itself. Each of the concentrations of gentamicin ultimately had an impact on the metabolic stress of the bacterial culture, which in the evaluation of the beginning RFUs to the end RFUs was significant, as shown in Figure 11A versus Figure 11B.

(A)

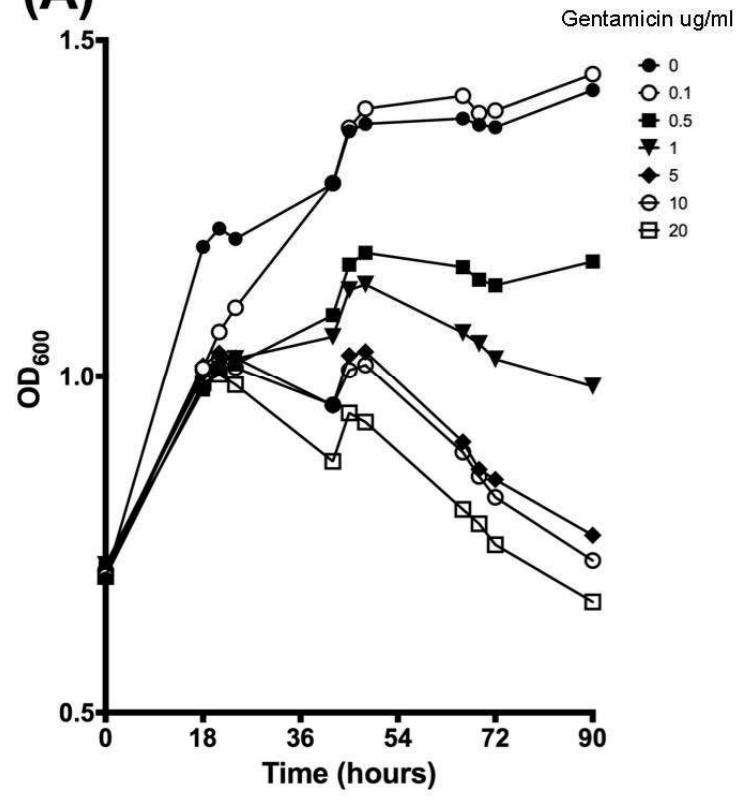

(B)

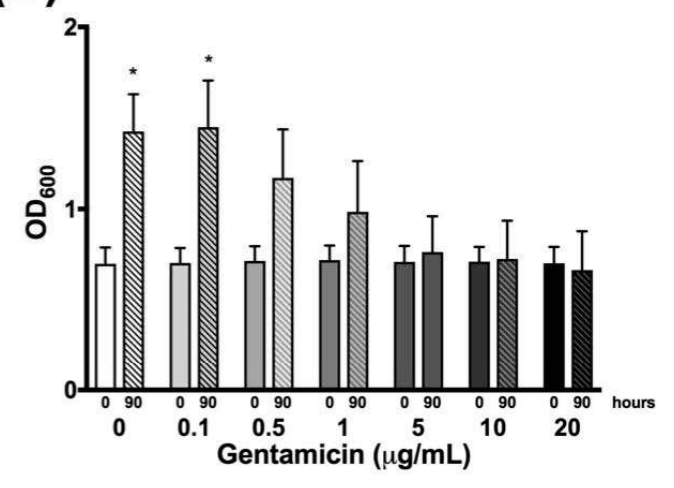

Figure 7. Optical density (OD) assay of M. avium gentamicin dose response. (A) OD of M. avium with gentamicin treatment over $90 \mathrm{~h}$ at $600 \mathrm{~nm}$. Differences between the slopes of each treatment are significant at $p<0.0001$ according to linear regression analysis. Average values are reported without error bars for graph clarity. (B) Optical density (OD) of M. avium with gentamicin treatment at time zero and 90 h. M. avium demonstrated increased OD with 0 and $0.1 \mu \mathrm{g} / \mathrm{mL}$ gentamicin treatment at ${ }^{*} p<0.05$ according to two-tailed, paired T-test analysis. M. avium treated with higher doses of gentamicin were not significant, $n=3$. 
Table 1. Mean and standard deviation of optical density $\left(\mathrm{OD}_{600}\right)$ for M. avium with gentamicin treatment over $90 \mathrm{~h}, n=3$.

\begin{tabular}{|c|c|c|c|c|c|c|c|c|c|c|c|c|c|c|}
\hline \multirow{2}{*}{ Time (h) } & \multicolumn{2}{|c|}{$0 \mu \mathrm{g} / \mathrm{mL}$} & \multicolumn{2}{|c|}{$0.1 \mu \mathrm{g} / \mathrm{mL}$} & \multicolumn{2}{|c|}{$0.5 \mu \mathrm{g} / \mathrm{mL}$} & \multicolumn{2}{|c|}{$1 \mu \mathrm{g} / \mathrm{mL}$} & \multicolumn{2}{|c|}{$5 \mu \mathrm{g} / \mathrm{mL}$} & \multicolumn{2}{|c|}{$10 \mu \mathrm{g} / \mathrm{mL}$} & \multicolumn{2}{|c|}{$20 \mu \mathrm{g} / \mathrm{mL}$} \\
\hline & Mean & SD & Mean & SD & Mean & SD & Mean & SD & Mean & SD & Mean & SD & Mean & SD \\
\hline 0 & 0.699 & 0.090 & 0.703 & 0.082 & 0.715 & 0.081 & 0.719 & 0.080 & 0.710 & 0.087 & 0.711 & 0.081 & 0.702 & 0.089 \\
\hline 18 & 1.193 & 0.344 & 1.012 & 0.068 & 0.980 & 0.039 & 1.000 & 0.041 & 1.016 & 0.031 & 1.009 & 0.021 & 0.990 & 0.040 \\
\hline 21 & 1.220 & 0.296 & 1.067 & 0.070 & 1.011 & 0.029 & 1.025 & 0.036 & 1.035 & 0.018 & 1.027 & 0.007 & 1.003 & 0.024 \\
\hline 24 & 1.205 & 0.213 & 1.103 & 0.064 & 1.018 & 0.010 & 1.027 & 0.042 & 1.028 & 0.036 & 1.013 & 0.042 & 0.987 & 0.036 \\
\hline 42 & 1.286 & 0.055 & 1.288 & 0.035 & 1.092 & 0.081 & 1.059 & 0.133 & 0.956 & 0.142 & 0.957 & 0.159 & 0.873 & 0.122 \\
\hline 45 & 1.365 & 0.148 & 1.370 & 0.130 & 1.167 & 0.049 & 1.129 & 0.022 & 1.031 & 0.042 & 1.009 & 0.040 & 0.945 & 0.059 \\
\hline 48 & 1.376 & 0.148 & 1.398 & 0.165 & 1.184 & 0.083 & 1.137 & 0.021 & 1.037 & 0.008 & 1.017 & 0.030 & 0.931 & 0.069 \\
\hline 66 & 1.384 & 0.171 & 1.417 & 0.210 & 1.163 & 0.199 & 1.065 & 0.159 & 0.902 & 0.094 & 0.887 & 0.126 & 0.802 & 0.105 \\
\hline 69 & 1.374 & 0.166 & 1.392 & 0.205 & 1.144 & 0.213 & 1.049 & 0.168 & 0.861 & 0.110 & 0.851 & 0.139 & 0.780 & 0.120 \\
\hline 72 & 1.371 & 0.185 & 1.395 & 0.232 & 1.136 & 0.239 & 1.026 & 0.202 & 0.846 & 0.147 & 0.820 & 0.177 & 0.749 & 0.145 \\
\hline 90 & 1.426 & 0.204 & 1.450 & 0.256 & 1.171 & 0.266 & 0.985 & 0.278 & 0.763 & 0.196 & 0.726 & 0.210 & 0.664 & 0.214 \\
\hline
\end{tabular}

(A)

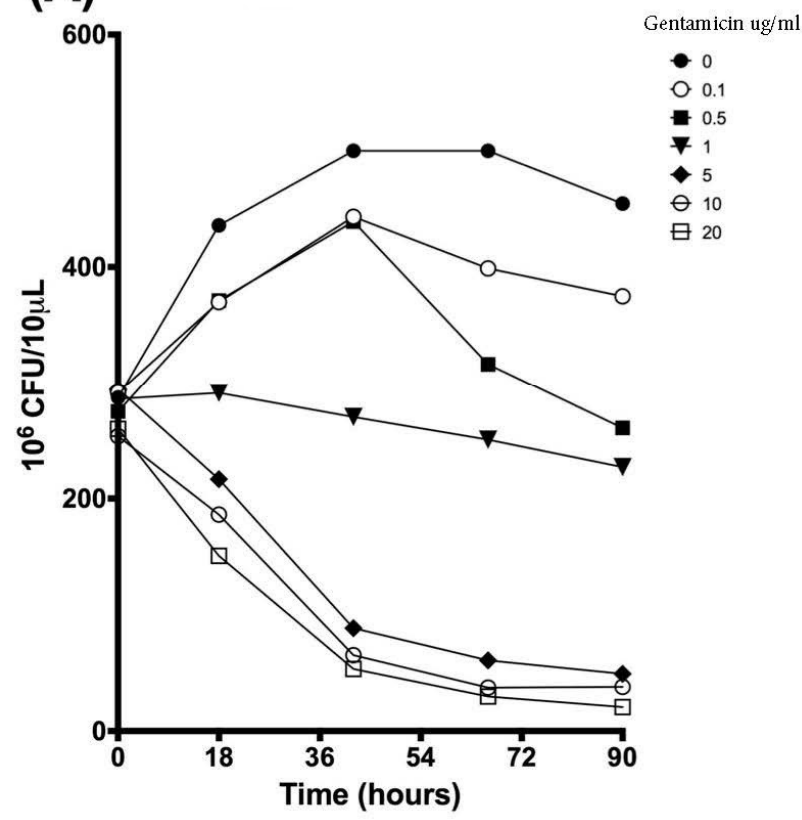

(B)

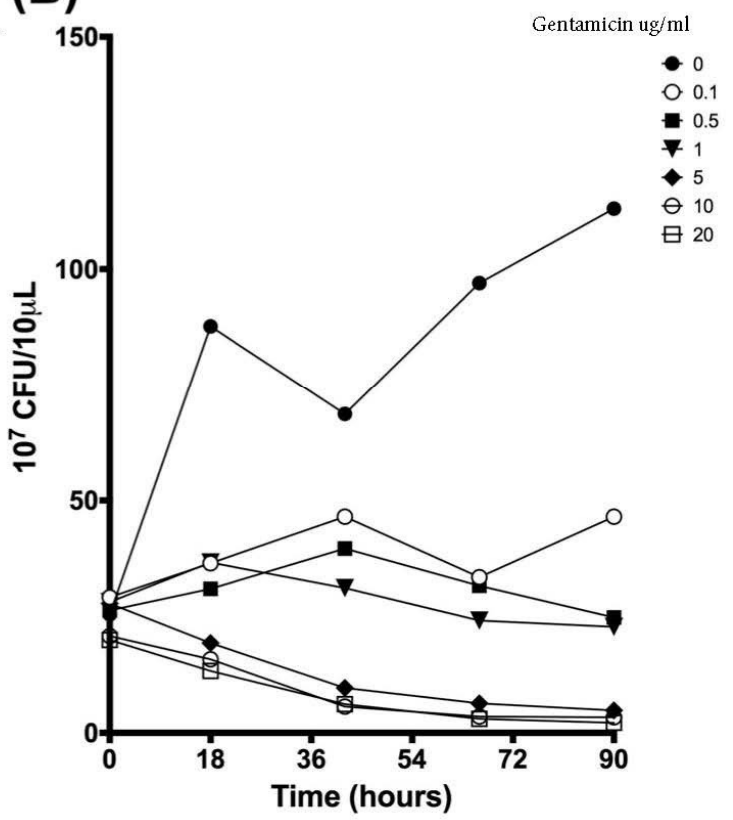

Figure 8. Growth kinetics of M. avium with gentamicin treatment over $90 \mathrm{~h}$ at (A) $10^{-6}$ dilutions. Differences between the slopes of each treatment are significant at $p<0.01$ according to linear regression analysis. Average values are reported without error bars for graph clarity. (B) $10^{-7}$ dilutions. Differences between the slopes of each treatment are significant at $p<0.0001$ according to linear regression analysis, $n=3$.

Table 2. Mean and standard deviation of bacterial growth (CFU) at $10^{6}$ dilutions for M. avium with gentamicin treatment over $90 \mathrm{~h}, n=3$.

\begin{tabular}{|c|c|c|c|c|c|c|c|c|c|c|c|c|c|c|}
\hline \multirow{2}{*}{ Time (h) } & \multicolumn{2}{|c|}{$0 \mu \mathrm{g} / \mathrm{mL}$} & \multicolumn{2}{|c|}{$0.1 \mu \mathrm{g} / \mathrm{mL}$} & \multicolumn{2}{|c|}{$0.5 \mu \mathrm{g} / \mathrm{mL}$} & \multicolumn{2}{|c|}{$1 \mu \mathrm{g} / \mathrm{mL}$} & \multicolumn{2}{|c|}{$5 \mu \mathrm{g} / \mathrm{mL}$} & \multicolumn{2}{|c|}{$10 \mu \mathrm{g} / \mathrm{mL}$} & \multicolumn{2}{|c|}{$20 \mu \mathrm{g} / \mathrm{mL}$} \\
\hline & Mean & SD & Mean & SD & Mean & SD & Mean & SD & Mean & SD & Mean & SD & Mean & SD \\
\hline 0 & 2872 & 31.8 & 2917 & 27.0 & 275.0 & 32.4 & 6.0 & 8.5 & 94.5 & 18.5 & 53.7 & 39.3 & 60.0 & 33.8 \\
\hline $1 \varepsilon$ & & 111.1 & 8 & 112.9 & 37 & 113.0 & 1.2 & 26 & 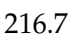 & 70 & .2 & 80.4 & 7 & 64.8 \\
\hline 42 & .0 & 0 & 443.2 & 98.4 & 439.2 & 105.4 & 270.3 & 24.5 & 88.5 & 25.1 & 65.3 & 35.5 & 3. & 19.3 \\
\hline 6 & 0.0 & 0.0 & 98.8 & 88.9 & 316.2 & 31.8 & 250.7 & 46.0 & 60.8 & 23.8 & 37 & 16.2 & 29. & 8.1 \\
\hline 90 & 454.5 & 78.8 & 374.8 & 12.1 & 260.8 & 20.3 & 227.0 & 68.8 & 49.2 & 21.4 & 38.0 & 23.4 & 20.7 & 7.3 \\
\hline
\end{tabular}


Table 3. Mean and standard deviation of bacterial growth (CFU) at $10^{7}$ dilutions for M. avium with gentamicin treatment over $90 \mathrm{~h}, n=3$.

\begin{tabular}{ccc|cc|cc|cc|cc|cc|cc}
\hline \multirow{2}{*}{ Time (h) } & \multicolumn{2}{c|}{$\mathbf{0} \boldsymbol{\mu g} / \mathbf{m L}$} & \multicolumn{2}{c|}{$\mathbf{0 . 1} \boldsymbol{\mu g} / \mathbf{m L}$} & \multicolumn{2}{c|}{$\mathbf{0 . 5} \boldsymbol{\mu g} / \mathbf{m L}$} & \multicolumn{2}{c|}{$\mathbf{1} \boldsymbol{\mu g} / \mathbf{m L}$} & \multicolumn{2}{c|}{$\mathbf{\mu g} / \mathbf{m L}$} & \multicolumn{2}{c|}{$\mathbf{1 0} \boldsymbol{\mu g} / \mathbf{m L}$} & \multicolumn{2}{c}{$\mathbf{2 0} \boldsymbol{\mu g} / \mathbf{m L}$} \\
& $\mathbf{M e a n}$ & SD & Mean & SD & Mean & SD & Mean & SD & Mean & SD & Mean & SD & Mean & SD \\
\hline 0 & 25.5 & 3.5 & 29.2 & 6.3 & 26.3 & 3.4 & 28.2 & 5.3 & 27.8 & 2.8 & 20.8 & 2.0 & 20.0 & 3.0 \\
18 & 87.7 & 78.8 & 36.5 & 7.9 & 31.0 & 3.0 & 36.7 & 9.8 & 19.3 & 6.9 & 15.8 & 10.6 & 13.3 & 5.0 \\
42 & 68.7 & 8.7 & 46.5 & 20.0 & 39.7 & 7.3 & 31.2 & 10.7 & 9.7 & 3.3 & 5.7 & 1.6 & 6.2 & 2.8 \\
66 & 97.0 & 28.8 & 33.5 & 5.2 & 31.7 & 6.3 & 24.2 & 4.5 & 6.3 & 1.4 & 3.5 & 1.3 & 3.0 & 1.0 \\
90 & 113.0 & 57.7 & 46.5 & 8.2 & 24.8 & 4.0 & 22.8 & 10.6 & 4.8 & 2.3 & 3.3 & 1.3 & 2.2 & 0.3 \\
\hline
\end{tabular}
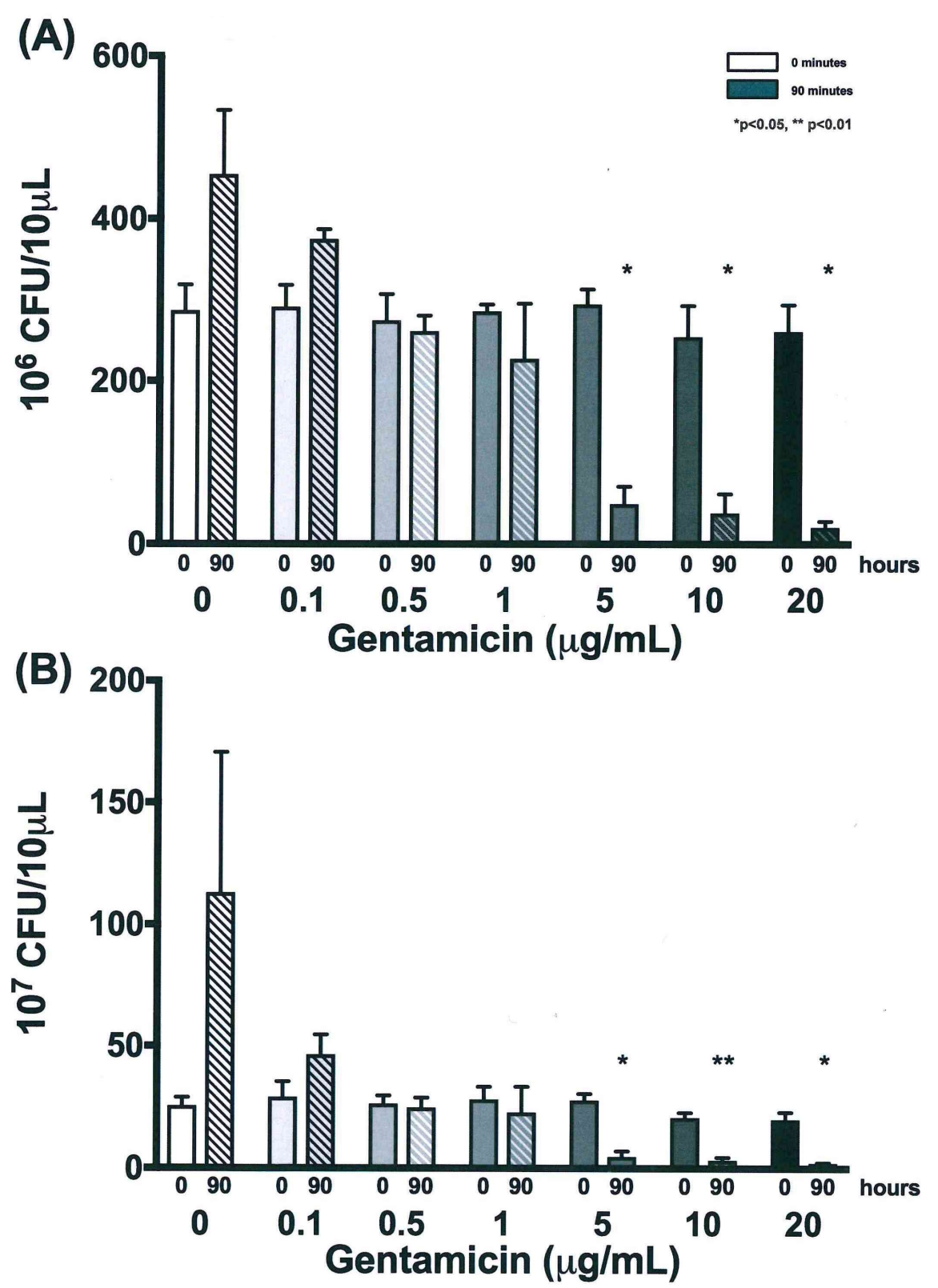

Figure 9. Growth of M. avium with gentamicin treatment at time zero and $90 \mathrm{~h}$ using colony forming units at (A) $10^{-6}$ dilutions. Decreased CFUs after $90 \mathrm{~h}$ for 5, 10, and $20 \mu \mathrm{g} / \mathrm{mL}$ gentamicin treatments were significant at ${ }^{*} p<0.05$ according to two-tailed, paired T-test analysis. M. avium treated with lower doses of gentamicin were not significant. (B) $10^{-7}$ dilutions. Decreased CFUs after $90 \mathrm{~h}$ were significant for 5 and $20 \mu \mathrm{g} / \mathrm{mL}$ gentamicin treatments at $* p<0.05$ and for $10 \mu \mathrm{g} / \mathrm{mL}$ gentamicin treatment at ${ }^{* *} p<0.01$ according to two-tailed, paired T-test analysis. M. avium treated with lower doses of gentamicin were not significant, $n=3$. 
(A)

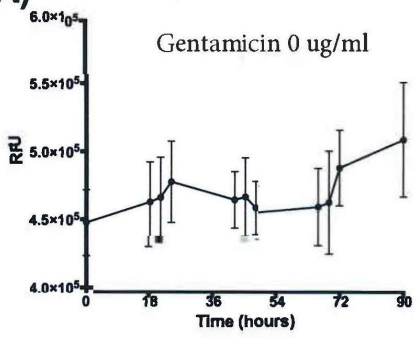

(D)

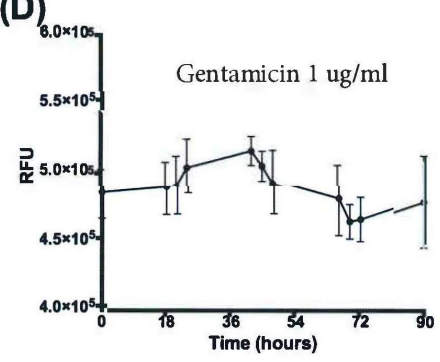

(G)

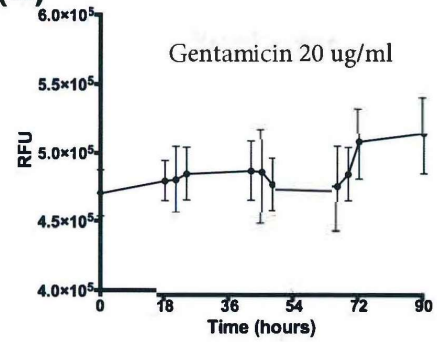

(B)

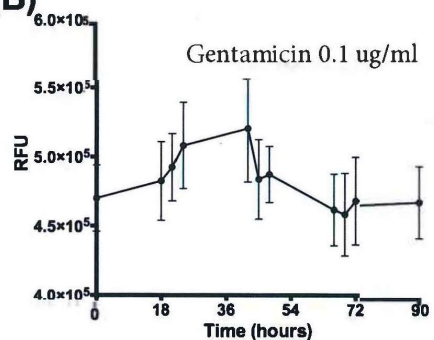

(E)

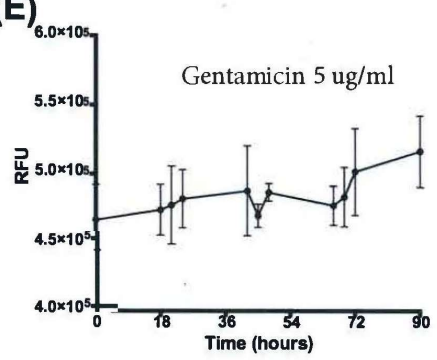

(C)

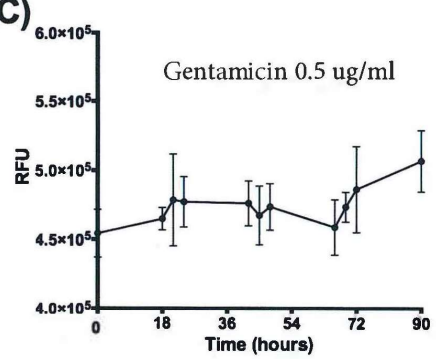

(F)

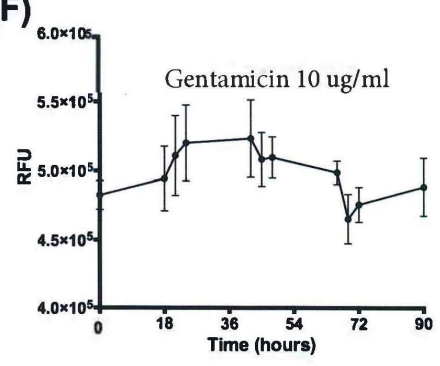

Figure 10. Cellular metabolic activity of M. avium with gentamicin treatment over $90 \mathrm{~h}$. (A) $0 \mu \mathrm{g} / \mathrm{mL}$ gentamicin. (B) $0.1 \mu \mathrm{g} / \mathrm{mL}$ gentamicin. (C) $0.5 \mu \mathrm{g} / \mathrm{mL}$ gentamicin. (D) $1 \mu \mathrm{g} / \mathrm{mL}$ gentamicin. (E) $5 \mu \mathrm{g} / \mathrm{mL}$ gentamicin. (F) $10 \mu \mathrm{g} / \mathrm{mL}$ gentamicin. (G) $20 \mu \mathrm{g} / \mathrm{mL}$ gentamicin. Differences between the slopes of each treatment are significant at $p<0.001$ according to linear regression analysis, $n=3$.

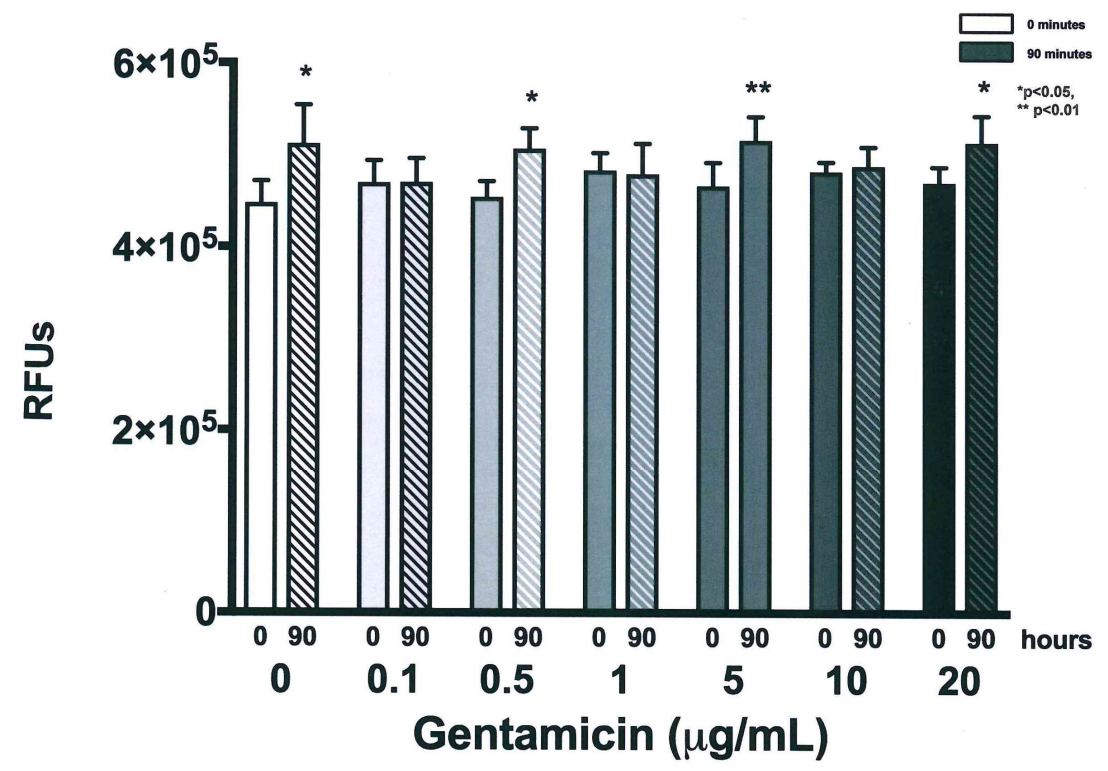

(A)

Figure 11. Cont. 


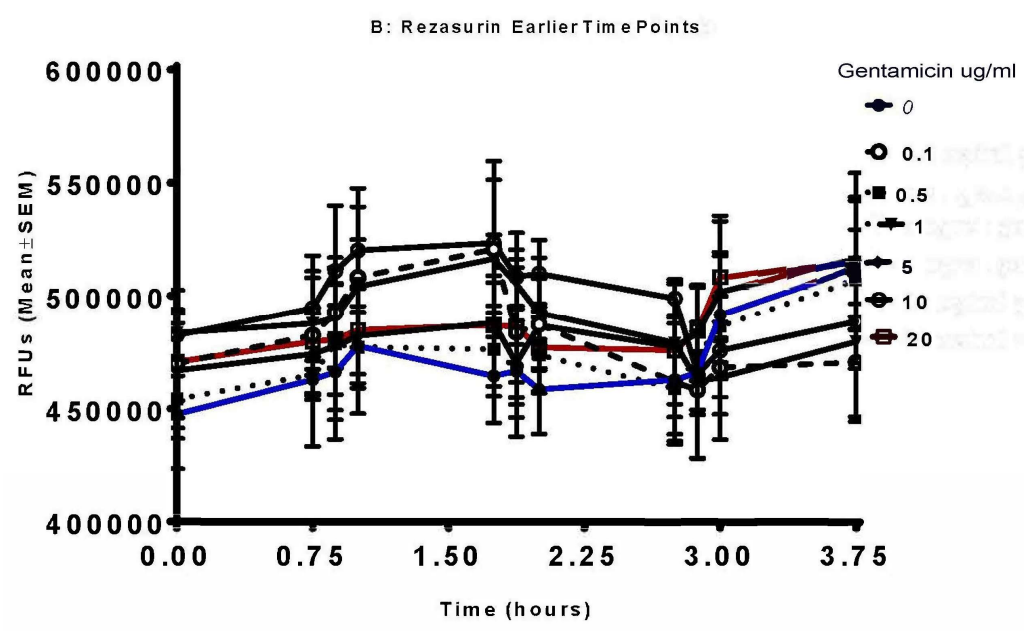

(B)

Figure 11. Cellular metabolic activity of M. avium with gentamicin treatment at time zero and $90 \mathrm{~h}$. (A) Increased activity after $90 \mathrm{~h}$ was significant for $0,0.5$, and $20 \mu \mathrm{g} / \mathrm{mL}$ at $* p<0.05$ and for $5 \mu \mathrm{g} / \mathrm{mL}$ at ${ }^{* *} p<0.01$ according to two-tailed, paired $T$-test analysis when comparing to the initial 0 -minute time point, $n=3$. (B) The cyclic nature of the metabolism of $M$. avium over the course of the study in the presence and absence of the dose escalation of gentamicin. The blue line is without gentamicin, the red line is with the $20 \mu \mathrm{g} / \mathrm{mL}$ gentamicin dose.

In the final evaluation of the methodologies, a direct comparison was made between the metabolic stress levels of the bacteria, as shown in Figure 12A, the total number of bacteria as defined by OD, as shown in Figure 12B, and surviving bacteria as defined by CFUs, as shown in Figure 12C, focusing on M. avium. In this comparison, the metabolic stress was enhanced with the addition of the gentamicin in a dose-dependent fashion, whereas the total number and surviving bacteria slowly decrease as markers of less capacity to grow and less available to culture. These correlations are significant at $p<0.05$ in each comparison, with a greater relation $p<0.01$ for OD versus CFUs.
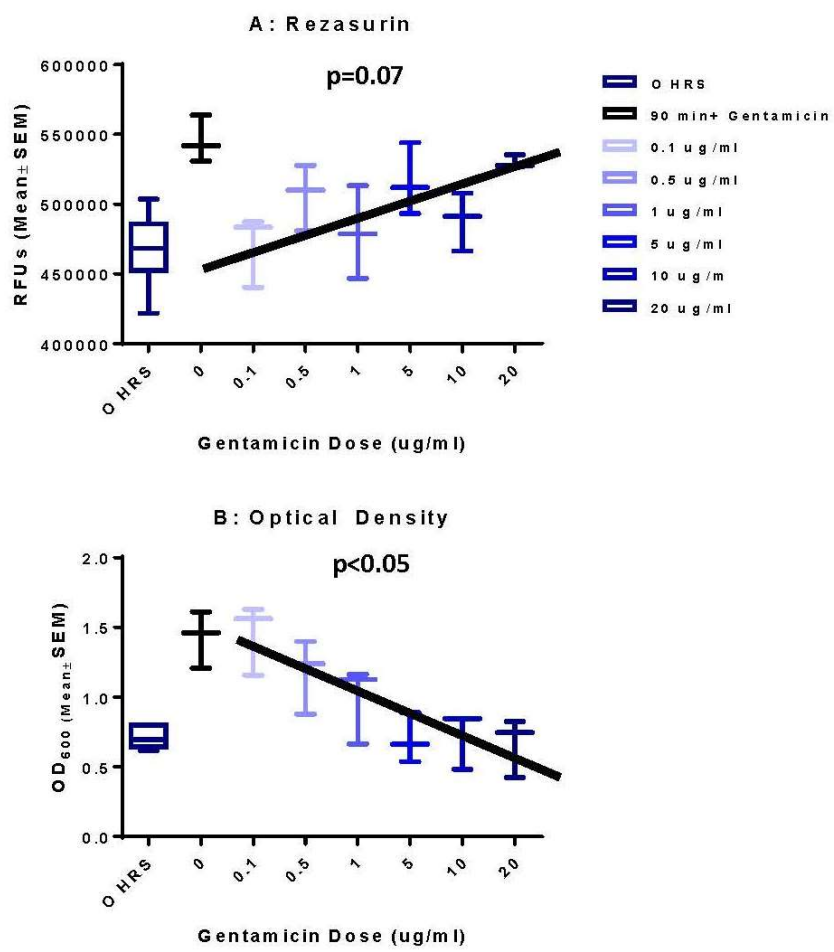

Figure 12. Cont. 


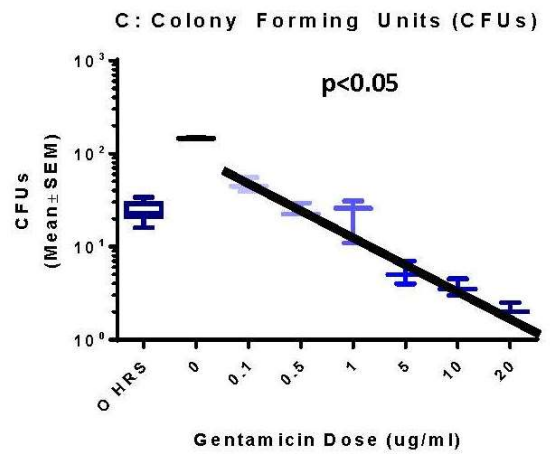

Figure 12. Linear regression comparison between the resazurin, $\mathrm{OD}$, and CFUs of growing M. avium in the presence and absence of dose escalation of gentamicin. The comparison is between the 0 time point and $90 \mathrm{~h}$ and the impact of the different concentrations of gentamicin over the course of the $90 \mathrm{~h}$. (A) Linear increase of resazurin as a component of enhanced stress, sub-statistical at $p=0.07$. (B) OD as a component of fewer numbers of bacteria over time, $p<0.05$. (C) CFUs demonstrating the surviving bacteria cultured at the end of each time point, $p<0.05$.

\section{Discussion}

New methods are desperately needed to evaluate therapeutics to treat $M A C$ and the bacterial species it comprises. The developed methodology outlined here provides a quick and effective way to observe the growth patterns of NTM, specifically those involved in MAC. The studies outlined in this manuscript successfully developed new protocols for monitoring growth of MAC species M. avium and $M$. intracellulare in a timeframe useful for therapeutic development and testing. These studies demonstrate the successful combination of both solid and broth media to enhance the growth of $M$. avium and $M$. intracellulare while still enabling observation of colony growth and morphology. Growing the bacteria in both supplemented broth and solid media allowed for the performance of weekly studies, illustrating its effectiveness in speeding up the typical growth time of these strains. During a 90-hour study, optical density and cellular activity can be measured at 11 time points and CFUs can be measured at five time points. Optical density data was measured immediately at each time point while the cellular activity of samples collected at each time point were measured at the end of $90 \mathrm{~h}$, using the resazurin assay. CFUs reflected the successful survival of the pathogens in the new growth protocols and show how the CFUs can be utilized for therapeutic testing and development. Although more detailed and specific technological approaches can be utilized with molecular biologic approaches, the need for a simplistic technology to monitor therapeutics over a variety of variables is essential for the initial clinical sensitivity testing. The pursuit of $M A C$ characterization using the four methods outlined in this manuscript to observe bacterial growth and activity optical density (OD), colony-forming units (CFU), the resazurin assay, and fluorescent labelling, provide the foundation for protocols which can be easily used to monitor new therapeutics.

Optical density is used to measure bacterial growth in real time [20]. In these studies, measuring $\mathrm{OD}$ at each time point demonstrated that $M$. avium, M. intracellulare, and $M A C$ can be monitored over a 90-hour experiment window. A comparison of OD at zero and $90 \mathrm{~h}$ indicated that there was significant growth of each bacterial strain independently and when combined at a p-value less than .01. The OD can indicate the likelihood of bacterial growth on agar plates for determination of MAC CFUs. However, OD cannot accurately predict bacterial count on its own and often underestimates growth once bacteria reach maximum cell density, as defined by "too numerous to count" (TNTC) [20,21].

To supplement data collected using OD, CFUs were calculated using a serial dilution and plate counting technique, determining bacterial growth after a one-week incubation period. This method is accurate even when accounting for dilution errors up to 10\% [22]. By plating bacteria at time points throughout the experiments, CFUs were calculated and analyzed to create bacterial growth curves for M. avium, M. intracellulare, and MAC. Comparing different dilutions of the bacteria provided insight 
towards the optimization of CFU counts and growth curve kinetics. CFU counts at $10^{-6}$ dilutions revealed increased growth of $M$. intracellulare over the 90-hour experiment at a significant level of .01 . Similar growth trends were observed at $10^{-7}$ dilutions for M. avium and MAC. Diluting the bacteria to $10^{-7}$ also demonstrated increased growth for $M$. intracellulare, but at a $\mathrm{p}$-value of .05 . These observations are consistent with the OD data, indicating overall growth over a 90-hour period, with M. avium exhibiting a strong influence over this trend. M. avium had higher CFU overall and MAC displayed increased counts when compared to $M$. intracellulare grown independently.

Bacterial activity was also measured using the resazurin assay, which allows for observation of small volumes of solution without the use a spectrometer [23]. The resazurin assay measures growth by detecting fluorescence as an indicator of cellular metabolic activity [21]. Resazurin data indicated that metabolic activity of M. avium, M. intracellulare, and $M A C$ followed a cyclic pattern resulting from intraand intercellular activity within the bacterial milieu. This pattern may be an indicator of the cell cycle, with higher fluorescence levels correlating to DNA replication and bacterial propagation and lower levels correlating to dormant phases of the cycle. The detected fluorescence results from the ability of metabolically active cells to reduce the resazurin dye to resorufin and dihydroresorufin, indicating their viability as a measure of cell proliferation [24]. After $90 \mathrm{~h}$, activity significantly increased for the bacterial flasks containing M. avium, consistent with OD and CFU data that suggest the strain's stability and dominance both grown independently and when combined (in $M A C$ ). The overall activity of $M$. intracellulare appeared to decrease over the same duration of time.

A combination of using OD, CFU, and the resazurin assay allowed for comprehensive measurement of bacterial growth and metabolic activity and comparison between the three methods. Measuring OD and CFU provided similar data, a quantification of growth of each bacterial strain over the 90 -hour period. The resazurin assay provided metabolic activity of each strain over the course of the experiment, suggesting growth fluctuations related to the cell cycle. Statistical analysis of these three tests indicates that significant bacterial growth occurred for M. avium, M. intracellulare, and $M A C$. Each methodology provided a unique way to characterize the growth patterns of these bacterial strains and together provide a more complete methodology with which to measure growth kinetics and monitor anti-MAC therapeutics in a short, replicable period. The application of the techniques to explore therapeutics was evaluated using the M. avium response to gentamicin confirmed assay sensitivity and the ability to evaluate growth kinetics in response to therapeutic treatment. $M$. intracellulare and $M A C$ had similar growth profiles as defined by the extensive studies outlined here and have similar predictive levels of sensitivity and specificity. In the M. avium studies, stunted OD growth was observed as the gentamicin dose was increased, indicating less available bacteria after $90 \mathrm{~h}$. Decreased CFUs confirmed decreased growth and viability of $M$. avium with higher doses of gentamicin. However, resazurin data indicated that cellular metabolic activity was not dose-dependent like OD and CFUs, but still changed according to different gentamicin treatments. Since gentamicin's antibiotic activity stems from its ability to block protein translation through ribosome binding [25], higher doses of gentamicin would further obstruct protein translation and stunt growth, explaining the decreased OD and CFU values for the gentamicin dose-response study. NTMs are sensitive to gentamicin, and although it is not the most potent antibiotic in the treatment arsenal, it was used to define the sensitivity and specificity of a gentamicin response [26]. Other treatment options being currently explored include aminoglycosides, clofazimine, bedaquiline, and dapsone, however each of these have varying levels of effectiveness against $M$. avium, $M$. intracellulare, and $M A C$ [26-28]. NTMs in chronic lung diseases do not infect these patients as singular entities; other pathogens often treated with gentamicin, such as Pseudomonas aeruginosa co-colonize [29,30]. Cellular metabolic activity, as detected by the resazurin assay, may not be dose dependent because, rather than testing for bacterial growth and viability, it detects metabolic activity of the remaining bacterial cells [28,31]. The cyclic nature of this activity could reveal opportune times to give therapeutics based on metabolic timing or the bacteria's growth kinetics overall. The ability to quantify growth and metabolic activity of mycobacterial strains will be important in determining type of treatment, dosage, and timing of drug 
delivery as well as further characterization of MAC and other NTM diseases [26]. The ability to detect gentamicin sensitivity and specificity in the protocols validates the capacity to utilize these methods for therapeutic development. It is of importance to note that gentamicin inhibitory activity on $M$. avium is $\mathrm{pH}$ dependent, adding another layer of complexity to NTM ongoing studies. In this manuscript, all studies were carried out at the homeostatic $\mathrm{pH}$ of 7.5 as a baseline for characterization, however, alterations of these culture conditions could change antibiotic impact as well as baseline growth kinetics [32,33].

Given the rapid development of new strains of NTM and their varying clinical presentations, initial clinical sensitivity testing that is fairly rapid and straightforward to carry out is contraindicated $[28,30]$. The success of this protocol in observing the individual mycobacterial strain growth and as part of $M A C$ suggests that it could be used to differentiate additional mycobacterial strains that comprise $M A C$ and offer new directions for therapeutic studies aimed at attenuation of the disease [31,33].

Author Contributions: L.A.: Data generation, analysis, manuscript writing; M.S.: Data generation analysis, manuscript writing; M.-C.G.: Methods development, data analysis; C.N.: Data analysis; T.L.B.: Experimental design, data analysis and statistics, manuscript writing.

Funding: The research was supported by the Marcus Foundation and the David and Virginia Baldwin Fund.

Acknowledgments: We would like to thank the Marcus Foundation and the Summer Programs in Undergraduate Research (SPUR) for their support of the project. We would also like to thank the laboratory of Dr. Bonfield, including David Fletcher, Christian vanHeeckeren, and Vaishnavi Ragavapuram for their mentorship and guidance on this student project.

Conflicts of Interest: The authors declare that they have no financial and/or commercial conflicts of interest.

\section{References}

1. Griffith, D.E.; Aksamit, T.; Brown-Elliott, B.A.; Catanzaro, A. An official ATS/IDSA statement: Diagnosis, treatment, and prevention of nontuberculous mycobacterial diseases. Am. J. Respir. Crit. Care Med. 2007, 175, 367-416. [CrossRef] [PubMed]

2. Tortoli, E. Microbiological features and clinical relevance of new species of the genus Mycobacterium. Clin. Microbiol. Rev. 2014, 27, 727-752. [CrossRef] [PubMed]

3. Inderlied, C.B.; Kemper, C.A.; Bermudez, L.E. The Mycobacterium avium complex. Clin. Microbiol. Rev. 1993, 6, 266-310. [CrossRef] [PubMed]

4. Olivier, K.N.; Weber, D.J.; Wallace, R.J.; Faiz, A.R. Nontuberculous mycobacteria: I: Multicenter prevalence study in cystic fibrosis. Am. J. Respir. Crit. Care Med. 2003, 167, 828-834. [CrossRef] [PubMed]

5. Lam, P.K.; Griffith, D.E.; Aksamit, T.R.; Ruoss, S.J. Factors related to response to intermittent treatment of Mycobacterium avium complex lung disease. Am. J. Respir. Crit. Care Med. 2006, 173, 283-1289. [CrossRef] [PubMed]

6. Ruoss, S.J. Pulmonary Infection in HIV-Negative Patients without Preexisting Lung Disease. Diagnostic and Management Limitations. Chest 1999, 115, 1033-1040.

7. Park, S.W.; Song, J.W.; Shim, T.S.; Park, M.S. Mycobacterial pulmonary infections in patients with idiopathic pulmonary fibrosis. J. Korean Med. Sci. 2012, 27, 896-900. [CrossRef] [PubMed]

8. Brown, B.A.; Wallace, R.J.; Onyi, G.O. Activities of clarithromycin against eight slowly growing species of nontuberculous mycobacteria, determined by using a broth microdilution MIC system. Antimicrob. Agents Chemother. 1992, 36, 1987-1990. [CrossRef]

9. Siddiqi, S.H.; Heifets, L.B.; Cynamon, M.H.; Hooper, N.M. Rapid broth macrodilution method for determination of MICs for Mycobacterium avium isolates. J. Clin. Microbiol. 1993, 31, 2332-2338.

10. American Thoracic Society. Diagnosis and Treatment of Disease Caused by Nontuberculous Mycobacteria. Am. J. Respir. Crit. Care Med. 1997, 156, S1-S25.

11. Menzies, D.; Nahid, P. Update in tuberculosis and nontuberculous mycobacterial disease 2012. Am. J. Respir. Crit. Care Med. 2013, 188, 923-927. [CrossRef] 
12. Koh, W.J.; Jeong, B.H.; Jeon, K.; Lee, N.Y. Clinical significance of the differentiation between Mycobacterium avium and Mycobacterium intracellulare in M avium complex lung disease. Chest 2012, 142, 1482-1488. [CrossRef]

13. Griffith, D.E.; Brown-Elliot, B.A.; Wallace, R.J. Hit the Road, MAC, and Don't You Come Back No More. Am. J. Respir. Crit. Care Med. 2015, 19, 1222-1224. [CrossRef] [PubMed]

14. Gomes, M.S.; Dom, G.; Pedrosa, J.; Boelaert, J.R. Effects of iron deprivation on Mycobacterium avium growth. Tuber Lung Dis. 1999, 79, 321-328. [CrossRef]

15. American Type Culture Collection ATCC Medium: 1395 Middlebrook 7H9 Broth w/ADC Enrichment. Available online: www.atcc.org/ \{\}/media/014FA24571954E679A363A23BE388F00.ashx (accessed on 6 January 2017).

16. American Type Culture Collection. Reviving Freeze-Dried Microorganisms Instructional Guide Reviving Freeze-. Available online: www.atcc.org/ \{\}/media/rfdc.ashx (accessed on 6 January 2017).

17. CellTiter-Blue ${ }^{\circledR}$ Cell Viability Assay. Promega. Available online: www.promega.com/-/media/files/ resources/protocols/technical-bulletins/101/celltiter-blue-cell-viability-assay-protocol.pdf (accessed on 6 January 2017).

18. Peeters, E.; Nelis, H.J.; Coenye, T. Comparison of multiple methods for quantification of microbial biofilms grown in microtiter plates. J. Microbiol. Methods 2008, 72, 157-165. [CrossRef] [PubMed]

19. Federle, M.J.; Bassler, B.L. Interspecies communication in bacteria. J. Clin. Investig. 2003, 112, 1291-1299. [CrossRef] [PubMed]

20. Begot, C.; Desnier, I.; Daudin, J.D.; Labadie, J.C. Recommendations for calculating growth parameters by optical density measurements. J. Microbiol. Methods 1996, 25, 225-232. [CrossRef]

21. Biesta-Peters, E.G.; Reij, M.W.; Joosten, H.; Gorris, L.G.M. Comparison of two optical-density-based methods and a plate count method for estimation of growth parameters of bacillus cereus. Appl. Environ. Microbiol. 2010, 76, 1399-1405. [CrossRef]

22. Ben-David, A.; Davidson, C.E. Estimation method for serial dilution experiments. J. Microbiol. Methods 2014, 107, 214-221. [CrossRef]

23. Sarker, S.D.; Nahar, L.; Kumarasamy, Y. Microtitre plate-based antibacterial assay incorporating resazurin as an indicator of cell growth, and its application in the in vitro antibacterial screening of phytochemicals. Methods 2007, 42, 321-324. [CrossRef]

24. Anoopkumar-Dukie, S.; Carey, J.B.; Conere, T.; O'Sullivan, E. Resazurin assay of radiation response in cultured cells. Br. J. Radiol. 2005, 78, 945-947. [CrossRef]

25. Yoshizawa, S.; Fourmy, D.; Puglisi, J.D. Structural origins of gentamicin antibiotic action. EMBO J. 1998, 17, 6437-6448. [CrossRef] [PubMed]

26. Huang, C.-C.; Wu, M.-F.; Chen, H.-C.; Huang, W.-C. In vitro activity of aminoglycosides, clofazimine, d-cycloserine and dapsone against 83 Mycobacterium avium complex clinical isolates. J. Microbiol. Immunol. Infect. 2018, 51, 636-643. [CrossRef] [PubMed]

27. Huh, H.J.; Kim, S.-Y.; Jhun, B.W.; Shin, S.J.; Koh, W.-J. Recent advances in molecular diagnostics and understanding mechanisms of drug resistance in nontuberculous mycobacterial diseases. Infect. Genet. Evol. 2018. [CrossRef] [PubMed]

28. Aguilar-Ayala, D.A.; Cnockaert, M.; André, E. In vitro activity of bedaquiline against rapidly growing nontuberculous mycobacteria. J. Med. Microbiol. 2017, 66, 1140-1143. [CrossRef] [PubMed]

29. Zemanick, E.T.; Sagel, S.D.; Harris, J.K. The airway microbiome in cystic fibrosis and implications for treatment. Curr. Opin. Paediatr. 2011, 23, 319-324. [CrossRef] [PubMed]

30. Kim, S.-Y.; Shin, S.H.; Moon, S.M.; Yang, B.; Kim, H.; Kwon, O.J.; Huh, H.J.; Ki, C.-S.; Lee, N.Y.; Shin, S.J.; et al. Distribution and clinical significance of Mycobacterium avium complex species isolated from respiratory specimens. Diagn. Microbiol. Infect. Dis. 2017, 88, 125-137. [CrossRef] [PubMed]

31. Portell-Buj, E.; Vergara, A.; Alejo, I.; López-Gavín, A.; Monté, M.; San Nicolás, L.; González-Martín, J.; Tudó, G. In vitro activity of 12 antimicrobial peptides against Mycobacterium tuberculosis and Mycobacterium avium clinical isolates. J. Med. Microbiol. 2018. [CrossRef] [PubMed] 
32. Heifets, L.B.; Lindholm-Levy, P.J.; Comstock, R.D. Bacteriostatic and bactericidal activities of gentamicin alone and in combination with clarithromycin against Mycobacterium avium. Antimicrob. Agents Chemother. 1992, 36, 1695-1698. [CrossRef]

33. Van Ingen, J.; Turenne, C.Y.; Tortoli, E.; Wallace, R.J., Jr.; Brown-Elliott, B.A. A definition of the Mycobacterium avium complex for taxonomical and clinical purposes, a review. Int. J. Syst. Evol. Microbiol. 2018, 68, 3666-3677. [CrossRef]

2019 by the authors. Licensee MDPI, Basel, Switzerland. This article is an open access article distributed under the terms and conditions of the Creative Commons Attribution (CC BY) license (http://creativecommons.org/licenses/by/4.0/). 